\title{
Liver morphology and function in visceral leishmaniasis (Kala-azar)
}

\author{
I A El Hag, F A Hashim, I A El Toum, $M$ Homeida, M El Kalifa, A M El Hassan
}

\begin{abstract}
Aim-To study the morphology and function of the liver in visceral leishmaniasis (Kala-azar).

Methods-Percutaneous liver biopsy specimens from 18 patients with confirmed visceral leishmaniasis were examined under light and electron microscopy before and after treatment with pentovalent antimony. The tissue was also examined for hepatitis $B$ surface and core antigens using immunoperoxidase staining. Liver function was investigated in nine patients before and after treatment. Results-Specimens before treatment showed Kupffer cells and macrophages colonised by leishmania parasites in $\mathbf{4 0} \%$ of cases. A chronic mononuclear cell infiltrate had affected the portal tracts and lobules. Ballooning degeneration of the hepatocytes, fibrosis of the terminal hepatic venules, and pericellular fibrosis were common findings. The fibrosis was related to Ito cells transforming to fibroblast-like cells. None of the patients had hepatitis B infection. All patients had biochemical evidence of liver dysfunction before treatment. Liver function improved after treatment.

Conclusion-Visceral leishmaniasis causes morphological and functional disturbance in the liver. Focal fibrosis rather than cirrhosis occurs. The exact aetiology of hepatic damage is unclear but may have an immunological basis.
\end{abstract}

$(\mathcal{F}$ Clin Pathol 1994;47:547-551)

Department of Pathology, Faculty of Medicine, University of Khartoum, PO Box 102, Khartoum, Sudan I A El Hag

I A El Toum

A M El Hassan

Department of

Physiology

F A Hashim

Department of

Internal Medicine

M Homeida

Department of

Pathology, Johns

Hopkins University,

Baltimore, USA

M El Kalifa

Correspondence to:

Professor Ahmed Mohamed

El Hassan.

Accepted for publication

14 December 1993
Visceral leishmaniasis is a major health problem in the Sudan. ${ }^{1}$ The disease is endemic in the eastern and southern part of the country and sometimes reaches epidemic proportions. ${ }^{23}$ In other parts of the world liver disease and various histopathological changes with some geographical variation have been described. These changes include diffuse Kupffer cells, hyperplasia with a heavy parasitic infiltrate, portal and intralobular granulomas, diffuse fibrosis ${ }^{45}$ and fibrin ring granuloma. ${ }^{6}$ Severe fibrogenic changes, the so-called Rogers' "cirrhosis", which is associated with liver dysfunction and portal hypertension, is more common in India than other endemic areas. ${ }^{5}$ In a recent study from India, however, no evidence of liver cirrhosis or portal hypertension in visceral leishmaniasis was found. ${ }^{7}$ Cases of severe hepatitis with cytoly- sis, cholestasis, and hepatic failure have been reported from Tunisia. ${ }^{8}$ The presence of the parasites inside the hepatocytes has been documented at the ultrastructural level and their role in relapse of the disease discussed. ${ }^{9}$ The pathogenesis of liver dysfunction and fibrosis and the role of Ito cells in aetiology of the latter are not well understood. We therefore decided to study liver pathology in visceral leishmaniasis and its evolution in relation to hepatic function and response to treatment. Furthermore, hepatic disease in Sudanese Kala-azar has not been reported before.

\section{Methods}

After informed consent 18 consecutive patients with confirmed visceral leishmaniasis were enrolled in the study. All patients were from the Bentiue area of southern Sudan or the Masairya tribe of the west. The parasites in both areas are of the same isoenzyme pattern. ${ }^{10}$ The male:female ratio was $5: 1$, ages ranged from 15 to 60 years. None of the patients had a history of alcoholism, jaundice, hepatosplenic schistosomiasis, or bleeding tendency. None was taking medication. There was no clinical evidence of liver failure in any of the patients. All had varying degrees of hepatosplenomegaly. Patients were treated with intravenous Pentostam $10 \mathrm{mg} / \mathrm{kg}$ body weight daily for 30 days.

Percutaneous needle liver biopsy specimens were taken from all patients before the start of treatment. A second liver biopsy specimen was obtained from only 13 patients within a week of completion of treatment. Biopsy specimens were fixed in formalin-mercuric chloride-acetic acid mixture for one hour, transferred to $70 \%$ ethanol, and processed for light microscopy. Paraffin wax sections (2-3 $\mu \mathrm{m})$ were stained with haematoxylin and eosin; collagen, reticulin, and iron were demonstrated by van Gieson stain, silver impregnation and Perls's Prussian blue reaction, respectively. Immunohistochemistry for hepatitis B virus was performed using the Dako PAP Kit system (Santa Barbara, California, USA) in which primary polyclonal antibodies against surface ( $\mathrm{HBsAg}$ ) and core ( $\mathrm{HBcAg}$ ) antigens of hepatitis $B$ virus were used. The manufacturer's instructions were followed. With each batch of test a known hepatitis B positive slide was included.

Pieces of liver tissue (1-2 mm long) were fixed in $2.5 \%$ glutaraldehyde at $4^{\circ} \mathrm{C}$ overnight and then transferred to cacodylate buffer $(\mathrm{pH}$ $7 \cdot 2$ ). The tissue was post-fixed in $1 \%$ osmium 
tetroxide and embedded in Epon. Ultrathin sections were stained with uranyl acetate and lead citrate and examined in a Phillips 300 transmission electron microscope.

Sera from nine patients before and after treatment as well as from 15 healthy subjects were tested for total protein, albumin, $\gamma$ glutamyltransferase (GGT), alkaline phosphatase, aspartate aminotransaminase (AST), alanine aminotransaminase (ALT), lactate dehydrogenase, total bilirubin and direct bilirubin.

The paired and unpaired two tailed Student's $t$ test were used.

\section{Results}

The main morphological changes seen under light microscopy were inflammation, parasite invasion of Kupffer cells, fibrosis, and hepatocyte changes in the form of swelling, dysplasia, and fatty change. Thrombosis was also seen.

INFLAMMATORY CHANGES

Inflammatory changes were seen in all liver biopsy specimens before treatment, both in the portal tracts (18 patients) and intralobularly (14 patients). Before treatment the portal tracts were enlarged and contained large numbers of macrophages, lymphocytes, and occasional plasma cells. There were no compact epithelioid granulomas nor Langhans' giant cells. In addition to this inflammatory reaction, mild to moderate fibrosis was seen in $28 \%$ of these specimens before treatment. In another $28 \%$ of cases limiting plates were irregular and there was evidence of piecemeal necrosis (fig 1 ).

After treatment the inflammation in the portal areas disappeared in $23 \%$, remained the same in $46 \%$, and increased in $31 \%$ of patients. Intralobular inflammation was seen in $14(78 \%)$ patients before treatment. It was diffuse in nature in $12(86 \%)$ of them. The inflammation consisted of hyperplastic and hypertrophic Kupffer cells and sinusoidal

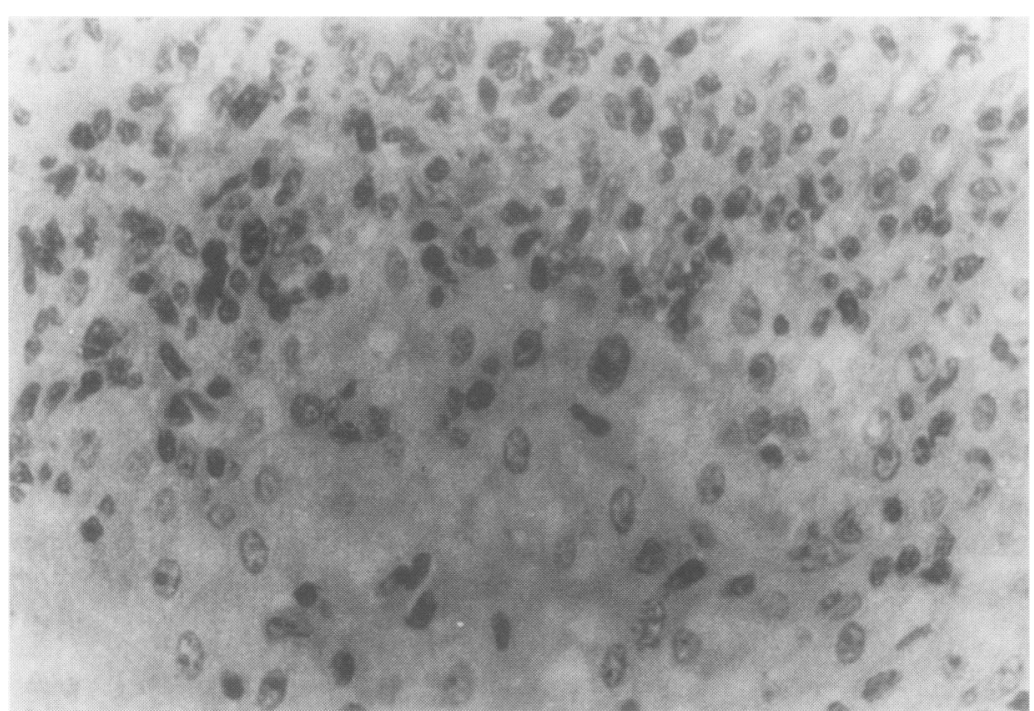

Figure 1 Edge of a portal tract showing an irregular limiting plate with moderately heavy mononuclear cell reaction infiltrating the hepatic parenchyma. A bile duct is at the top of the photograph (haematoxylin and eosin). inflammatory mononuclear cells. In the other two patients nodular collections of mononuclear cells were seen mainly around the central vein. After treatment intralobular inflammation was still present in seven out of $13(54 \%)$ patients.

Parasites were only identified in eight out of $18(44 \%)$ patients. The parasites were within the Kupffer cells and in histocytes in the portal tracts. Parasitised cells were usually associated with an inflammatory cellular reaction consisting of lymphocytes and plasma cells. Even before treatment in $56 \%$ of patients the inflammatory reaction contained no parasitised cells. No parasites were detected in the samples after treatment despite the presence of the inflammatory reaction.

\section{FIBROSIS}

Fibrosis of the central vein was seen in 10 out of $18(56 \%)$ patients before treatment and in 12 out of $13(92 \%)$ patients after treatment (fig 2). It was absent or seen in a milder form before treatment in patients with a nodular inflammatory reaction around central veins. It appeared in these areas or increased in severity after treatment.

Portal fibrosis was seen in 11 out of 13 $(85 \%)$ patients after treatment compared with five out of $18(28 \%)$ patients before treatment. Portal inflammatory reaction without fibrosis was seen in three cases before treatment. In these cases liver biopsy specimens taken after treatment showed only fibrosis without inflammation.

Pericellular fibrosis was seen after treatment in eight out of $13(62 \%)$ patients compared with five out of $18(28 \%)$ patients before treatment. It started around central veins and portal tracts and spread to encircle cells in the vicinity of these structures first (fig 2).

Bridges between different liver compartments were seen in five out of $18(28 \%)$ patients after treatment compared with two out of $18(11 \%)$ patients before treatment, with bridging seen before and after treatment in one case.

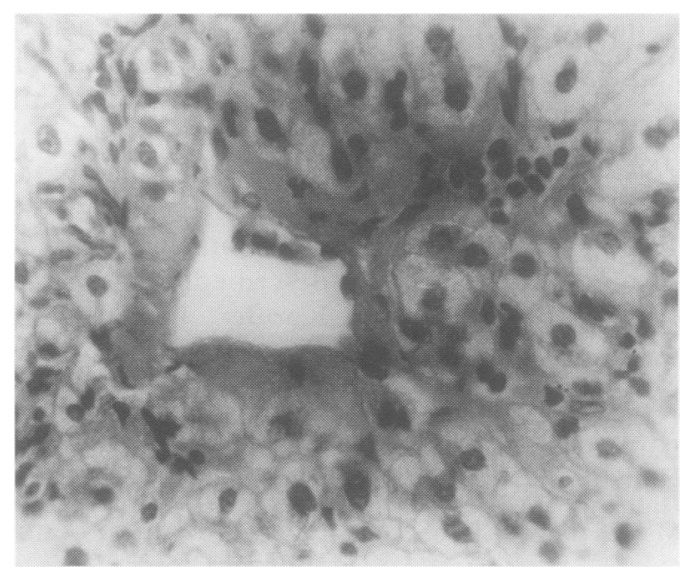

Figure 2 Fibrosis of the wall of a central vein. Note the fibrosis is extending into the surrounding liver parenchyma. Hepatocytes show ballooning degeneration (haematoxylin and eosin). 
Figure 3 Leishmania parasite inside two adjacent Kupffer cells. There is collagen between the two cells.

Figure 4 Hepatocytes showing pronounced oedema of the cytoplasm.

Figure 5 The bottom of the photograph shows part of the cytoplasm of an Ito cell containing many

filaments. At the top is a hepatocyte in intimate contact with the Ito cell.
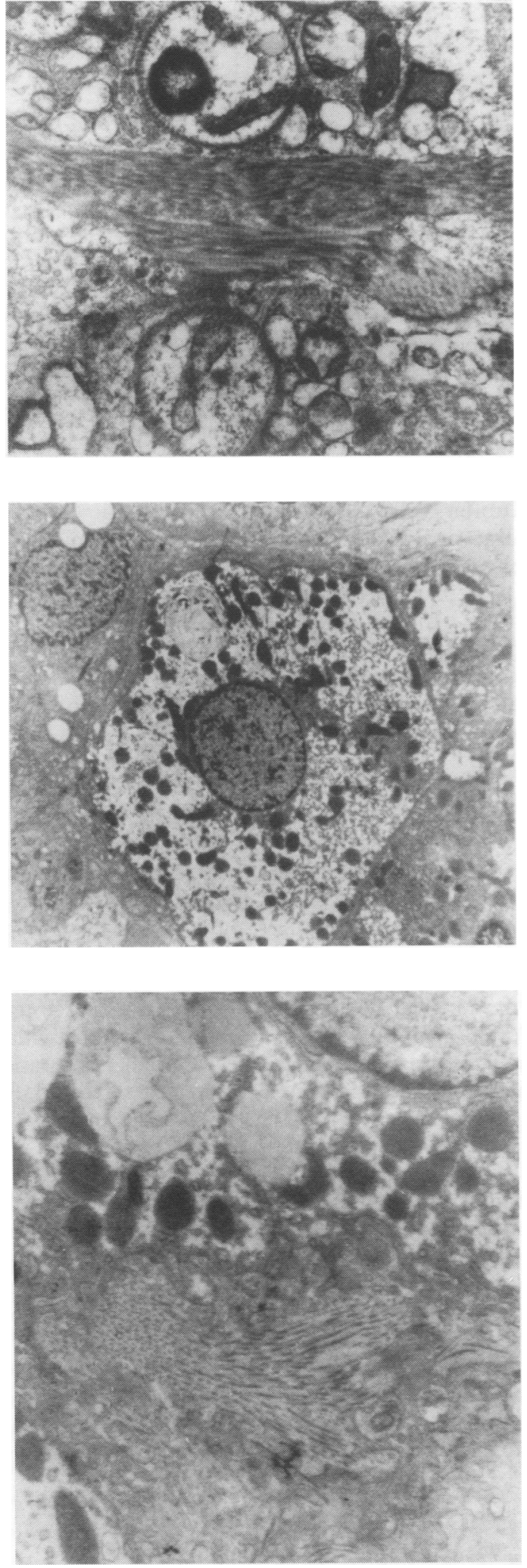

CHANGES IN HEPATOCYTES AND KUPFFER CELLS Swollen pale-staining hepatocytes were common and were seen in 11 out of $18(61 \%)$ patients before treatment and in 11 out of 13 $(85 \%)$ patients afterwards (fig 2 ). The swollen hepatocytes formed rosettes similar to those seen in chronic active hepatitis. Focal and individual hepatic cell necrosis was rarely encountered. Severe fatty change was seen in only one patient, who was very ill and who died five days after the start of treatment.
Dysplasia, defined by increased nuclear staining and pleomorphism, was seen in 12 out of $18(67 \%)$ patients before treatment. Dysplasia remained after treatment.

Parasitised Kupffer cells were hypertrophied and occasionally contained phagocytosed red cells.

Apoptotic Kupffer cells containing parasites were seen in three patients.

Increased iron content in hepatocytes and Kupffer cells was seen in all patients before and after treatment. It was more noticeable in Kupffer cells.

\section{THROMBOSIS}

Thrombosis was seen in six patients. In one patient an organised thrombus was found in a portal vein. In the remaining five patients sinusoidal thrombosis was widespread.

In all cases biopsy specimens were negative for HBsAG and HBcAG.

At electron microscopic examination, parasites were seen inside the Kupffer cells (fig 3). They were enveloped in a unit host membrane. The pellicular membrane showed typical microtubules. Internal structures included the nucleus, kinetoplasts, and the flagellar pocket. Erythrophagocytosis was observed in parasitised Kupffer cells.

Some hepatocytes showed dilatation of the endoplasmic reticulum and microvesicles surrounding the dilated endoplasmic reticulum. The latter showed disruption of the ribosomes. Some hepatocytes, particularly after treatment, showed pronounced oedema of the cytosol in addition to dilatation and disruption of the endoplasmic reticulum (fig 4).

Ito cells were identified by their typical large fat droplets. Some Ito cells showed extensive dilatation of their endoplasmic reticulum, a sign of increased secreting activity. In some areas cells in the typical position of Ito cells had no lipid droplets and showed intracytoplasmic filaments (fig 5). These were

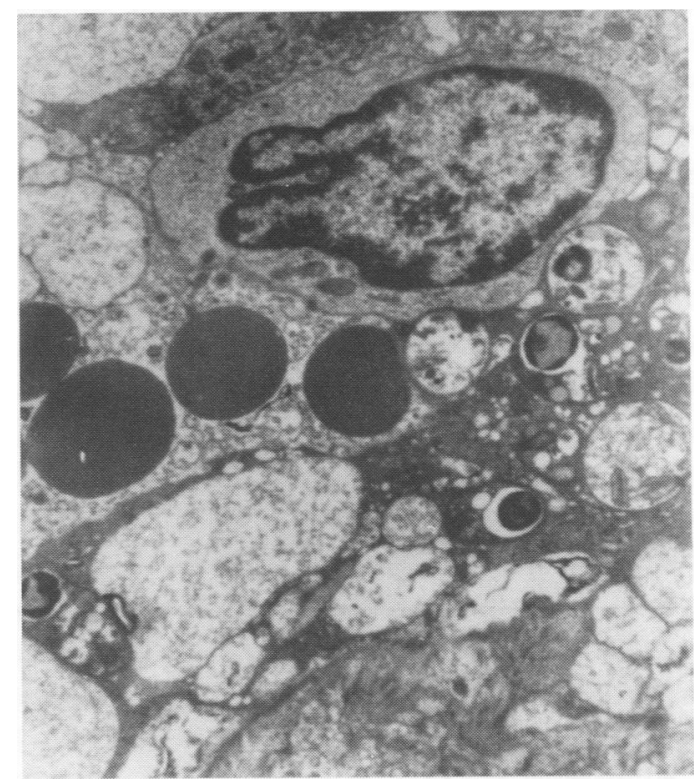

Figure 6 At the top is a lymphocyte in intimate contact with a parasitised Kupffer cell and an Ito cell. The latter contains lipid droplets. 
considered to be Ito cells completely transformed into fibroblast-like cells. Parasitised Kupffer cells, Ito cells, and lymphocytes were contiguous (fig 6).

Collagen fibres were seen around hepatocytes and occasionally between adjacent Kupffer cells (fig 3).

Before and after treatment alkaline phosphatase and GGT values were significantly higher in patients than controls (table). Other liver enzymes (ALT, AST, lactate dehydrogenase) were significantly higher in patients before treatment than in controls but they returned to normal after treatment.

\section{Discussion}

Morphological changes in the liver in visceral leishmaniasis involve Kupffer cells, hepatocytes, Ito cells, portal tracts, sinusoids and hepatic veins. Hypertrophy and hyperplasia of the Kupffer cells occur, and in $44 \%$ of cases these cells contain parasites. In about twothirds of patients the hepatocytes showed ballooning degeneration which worsened after treatment despite improved liver function after treatment. The hepatic changes were not related to the presence of parasites or to the inflammatory reaction in the biopsy specimens. In some samples that had been treated, in which parasites had been eliminated and the inflammation had subsided, ballooning degeneration was still evident. The pathogenesis of this change is unknown. Concomitant hepatitis B infection has been excluded. The fact that in some patients the hepatic changes worsen after treatment may be partly due to the effect of the drug. Functionally, the GGT and alkaline phosphatase values did not drop to normal after treatment, although serum albumin and other enzymes returned to normal. The piecemeal necrosis, seen even in the absence of demonstrable parasites, could mean an immunological injury to the hepatocytes, particularly at the periphery of the lobules. The inflammatory cellular reaction, which consists of parasitised macrophages, lymphocytes, and plasma cells, affects the portal tracts and is found inside the lobule either diffusely in the sinusoid or focally. Although parasites disappeared after treatment, the inflammatory reaction was still present or even increased after treatment in $77 \%$ of the patients. However, the patients recovered clinically and most of the liver function tests returned to normal. The only patient who died had severe fatty changes. We have already seen another patient who died of visceral leishmaniasis and had a fatty liver at necropsy. It seems that severe fatty change of the liver in visceral leishmaniasis is a sign of poor prognosis. Compact epithelioid granulomas and Langhans' giant cells do not occur. This contrasts with cutaneous leishmaniasis where well developed compact granulomas are associated with the development of a delayed hypersensitivity reaction, as indicated by a positive leishmanin test. ${ }^{11}$ Patients with visceral leishmaniasis are leishmanin negative and their peripheral mononuclear cells do not react to leishmania antigen. ${ }^{12}$ Patients with asymptomatic (subclinical) visceral leishmaniasis are leishmanin positive and show well developed epithelioid granuloma in the liver. ${ }^{13}$

Roger first described "cirrhotic" changes in patients with visceral leishmaniasis, in India in $1908 .^{14}$ It was not a true cirrhosis but a diffuse fibrosis, isolating small groups of hepatocytes, with evidence of regeneration. A better term for the change is diffuse intralobular fibrosis. ${ }^{4}$ Most of our patients showed fibrosis of the wall of the central veins and pericellular fibrosis in its vicinity. This was confirmed by electron microscopy. In some patients there was bridging fibrosis connecting central veins to portal tracts or portal tracts to portal tracts in parts of the liver. Because of the focal nature of the fibrosis, it is doubtful if these patients will ever progress to cirrhosis. Over the past three years, in a longitudinal study of visceral leishmaniasis in a village in an endemic area in the Sudan, no patient developed cirrhosis after being treated for visceral leishmaniasis (El Hassan, unpublished data). Long term follow up, which was not possible in our patients, is needed to determine the final outcome of the hepatic changes.

The source of fibrosis seems to be Ito cells. Regardless of the cause of hepatic injury, healing by fibrosis in the liver involves Ito cells. The fibrosis may follow physical injury, ${ }^{15}$ alcoholic liver disease, ${ }^{16}{ }^{17}$ and fatty liver of obesity. ${ }^{18}$ Transformation of Ito cells to fibroblast-like cells is believed to be the cause of fibrosis in these varied clinical situations. ${ }^{19}$ The most reliable indicator of transformation is

Mean (SD) Results of liver function tests in controls $(n=15)$ and patients $(n=9)$ before and after treatment

\begin{tabular}{|c|c|c|c|c|c|c|c|c|c|}
\hline & $\begin{array}{l}\text { Total } \\
\text { protein } \\
(g / d l)\end{array}$ & $\begin{array}{l}\text { Albumin } \\
\text { (mg/dl) }\end{array}$ & $\begin{array}{l}\text { Alkaline } \\
\text { phosphatase } \\
\text { (UII) }\end{array}$ & $\begin{array}{c}A L T \\
(U / l)\end{array}$ & $\begin{array}{l}\text { Lactate } \\
\text { dehydrogenase } \\
\text { (UIl) }\end{array}$ & $\begin{array}{l}G G T \\
(U / l)\end{array}$ & $\underset{\text { (UIl) }}{A S T}$ & $\begin{array}{l}\text { Total } \\
\text { bilirubin } \\
\text { (mg/dl) }\end{array}$ & $\begin{array}{l}\text { Direct } \\
\text { bilirubin } \\
\text { (mg/dl) }\end{array}$ \\
\hline $\begin{array}{l}\text { Control } \\
\text { Pre-treatment } \\
\text { Post-treatment }\end{array}$ & $\begin{array}{l}8.0(1.0) \\
7.4(2.9) \\
7.9(1.4)\end{array}$ & $\begin{array}{l}4.3(0.7) \\
2.8(0.7)^{a} \\
3.7(0.4)^{b}\end{array}$ & $\begin{array}{c}74(29) \\
234(221)^{c} \\
190(105)^{d}\end{array}$ & $\begin{array}{l}12(6) \\
57(50)^{e} \\
15(5)^{f}\end{array}$ & $\begin{array}{l}210(72) \\
352(172)^{\mathrm{g}} \\
156(29)^{\mathrm{h}}\end{array}$ & $\begin{array}{l}20(9) \\
66(54)^{i} \\
52(47)\end{array}$ & $\begin{array}{l}34(11) \\
159(121)^{j} \\
50(16)\end{array}$ & $\begin{array}{l}0.7(0.6) \\
0.4(0.1) \\
0.6(0.2)\end{array}$ & $\begin{array}{l}0.1(0.1) \\
0.2(0.1) \\
0.1(0.1)\end{array}$ \\
\hline \multicolumn{10}{|c|}{$\begin{array}{l}\text { Significantly different from: } \\
\text { a control, } \mathrm{p}<0.001 \text {. } \\
\text { b control and pre-treatment groups, } \mathrm{p}<0.02 \text { and } \mathrm{p}<0.01 \text {. } \\
\text { c control, } \mathrm{p}<0.05 \text {. } \\
\text { d control, } \mathrm{p}<0.01 \text {. } \\
\text { e control, }<0.02 \text {. } \\
\text { f pre-treatment, }<<0.05 \text {. } \\
\mathrm{g} \text { control, } \mathrm{p}<0.05 \text {. } \\
\text { h control and pre-treatment, } \mathrm{p}<0.02 \text {. } \\
\text { i control, }<<0.02 \text {. } \\
\text { j control and post-treatment, } \mathrm{p}<0.01 \text { and } \mathrm{p}<0.05 \text {. }\end{array}$} \\
\hline
\end{tabular}


dilatation and an increase in the rough endoplasmic reticulum rather than a change in the lipid content of these cells. ${ }^{19} \mathrm{We}$ found dilated endoplasmic reticulum in Ito cells and complete transformation of these cells into fibroblast-like cells. The stimulus for Ito cell transformation is probably mediated by cytokines. Transforming growth factor $\mathrm{B}_{1}$ produced by Kupffer cells, endothelial cells, and Ito cells induces synthesis of fibronectin, laminin, collagen and protoglycans and it also down-regulates collagenase expression. ${ }^{20}$ Interleukin 1 stimulates DNA synthesis and proliferation of Ito cells in primary culture, and platelet derived growth factor activates Ito cells towards a myofibroblast appearance. ${ }^{20}$ We have shown that parasitised Kupffer cells, Ito cells, and lymphocytes are contiguous. Activation of platelets was evidenced by microthrombi in the sinusoides of some patients.

We are indebted to Miss Wafaa Salih and Mr Sayed Osman Yousif of the electron microscopy unit, University of Khartoum, Susan Peters of the Department of Anatomy, University of Copenhagen, for technical assistance with electron microscopy, and $\mathrm{Mr}$ El Tahir Fadel for bone marrow biopsies. The hepatitis B kit was kindly donated by Dako A/S Denmark.

1 World health organization. Control of leishmaniasis. Report of WHO expert committee. No 793. WHO technical report series. Geneva: WHO. 1990.

2 Satti MH. Early phase of an out break of Kala-azar in the Southern fung. Sudan Med $₹$ 1958;1:98-111

3 Zijlstra EE, Siddig Ali M, El Hassan AM, El Toum IA, Satti M, Ghalib HW, et al. Kalaazar in displaced people from southem Sudan. 1. Epidemiological, clinical and therapeutic findings. Trans Roy Soc Trop Med Hyg 1991; 85:365-9.
4 Duarte MI, Corbett CEP. Histopathological patterns of the liver involvement in visceral leishmaniasis. Rev Inst Med Trop 1987;29:131-6.

5 Daneshbod K. Visceral leishmaniasis (Kala-zar) in Iran: a pathologic and electron microscopic study. Am $\mathcal{F}$ Clin Pathol 1972;57:156-66.

6 Moreno A, Marazuela M, Yebra M, Hernandoz MJ. Hepatic fibrin ring granuloma in visceral leishmaniasis. Gepatic fibrin ring granuloma in

7 Aggarwal P, Wali JP, Chopra P. Liver in Kala-zar. Indian 7 Gastroenterol 1990;9:135-6.

8 Khalddi F, Bennaceur B, Ben Othman H, Achouri E, Ayachi R, Ragareg R. Severe forms of liver involvement in visceral leishmaniasis. Arch Fr Pediatr 1990;47:257-60.

9 Duarte MI, Marino ON, Corbett CEP. Liver parenchymal cell parasitism in human visceral leishmaniasis. Virchows Arch (Coll Pathol) 1989;415:1-6.

10 El Hassan AM, Hashim FA, Siddig Ali M, Ghalib HW, Zijlstra EE. Kala-azar in western upper Nile in the southern Sudan and its spread to a nomadic tribe from the North. Trans Roy Soc Trop Med Hyg 1993;87:395-8.

11 Ridley DS, Ridley MS. Late stage cutaneous leishmaniasis: Immunopathology of tuberculoid lesions in skin and lymphnodes. Br ¥ Exp Pathol 1984;65:337-46.

12 Carvalho EM, Teixlira RS, Johnson WD, Jr. Cell mediated immunity in American visceral leishmaniasis: Reversible immunity in American visceral leishmaniasis: Reversible immunosuppressio

13 Pampiglione S, Manson-Bahar PEC, Giunti G, Parenti A, Canestri Trotti $G$. Studies of mediterranean leishmaniasis. 2. Asymptomatic cases of visceral leishmaniasis. Trans Roy Soc Trop Med Hyg 1974;68:447-53.

14 Rogers L. A peculiar intralobular cirrhosis of the liver produced by the protozoal parasites of Kala-azar. Ann Trop Med Parasitol 1908;2:147-52.

15 Ogawa K, Susuki JI, Narasaki M, Mori M. Healing of focal injury in the rat liver. Am $f$ Pathol 1985;119: 158-67.

16 Mak KM, Leo MA, Lieber CS. Alcoholic liver injury in baboons: Transformation of lipocytes to transitional baboons: Transformation of lipocytes

17 Minato Y, Hasumura Y, Takeuchi J. The role of fatstoring cells in Disse space fibrogenesis in alcoholic liver

18 Veno T, Noguchi K, Nogata E, Abe H, Tanchawa K. The changes of myofibroblast and fat-storing cell in fatty liver with obesity. Hepatology 1986;6:781.

19 French SW, Miyamoto K, Wong K, Jui L, Briere L. Role of the Ito cell in liver paranchymal fibrosis in rats fed alcohol and a high fat-low protein diet. Am $\mathcal{F}$ Pathol 1988; 132:73-84.

20 Clement B, Lorel O, Lawarsur F, Guellouzo A. New challenges in hepatic fibrosis. $\mathcal{F}$ Hepatol 1993;18:1-4. 